\title{
Habitat offsets for insect species conservation: practicality or placebo?
}

\author{
T. R. New
}

Published online: 25 November 2008

(C) Springer Science+Business Media B.V. 2008

Some formal call for mitigation of the perceived damage incurred to sites is an increasingly frequent demand on developers of sites of conservation significance. The broad theme of 'bio-offsets' is receiving increasing attention in many parts of the world. Wide discussion of the values of 'Environmental Offsets' under the federal Environment Protection and Biodiversity Conservation Act 1999 (EPBC) in Australia encompasses measures considered to counterbalance the impacts to biodiversity that result from development. They range from rather nebulous 'carbon offsets' to counter industrial emissions to more limited measures of considerable interest in conservation and management of habitats for threatened insect species. These predominantly involve consequences of clearing native vegetation, long acknowledged as a paramount threat to Australia's terrestrial biota. These measures may be purely voluntary, but are more commonly conditions of project approval, negotiated on a case-by-case basis, or more tangentially can be managed by some form of 'credit' purchased by developers in the form of a 'conservation bank'. Essentially, they fall into the category of direct offsets, to compensate for losses by providing a replacement habitat, or for enhancement of the remaining areas to increase carrying capacity - basically to at least result in 'no net loss' and no increased vulnerability to key species. However, there may be formal demand for a 'net gain', so that conservation benefits exceed the losses incurred from the development, or to 'maintain or improve' allowing flexibility for either standard to be met. At one level, the principle resembles a 'salvage operation', in which a duty

T. R. New $(\bowtie)$

Department of Zoology, La Trobe University,

Victoria 3086, Australia

e-mail: T.New@latrobe.edu.au of care (moral or legal) may (1) incur capture of individuals likely to otherwise be sacrificed, either for direct translocation or to some ex situ situation for later release; or (2) provide opportunity for natural dispersal to the offset habitat. The Australian government's definition of 'environmental offsets' is 'actions taken outside a development site that compensate for the impacts of that developmentincluding direct, indirect or consequential impacts' (Australian Government 2007). The policy background is discussed by Gibbons and Lindenmayer (2007), who emphasized that offsets should not be used to justify land clearing, and that offsets might be feasible (1) only for relatively simple vegetation types that can indeed be restored; (2) where the offset must be in place before loss of the original site occurs; (3) where management of the offset site is adaptive; and (4) that the offset sites must be secured for the future. Compliance issues may be difficult to ensure. The first condition is important: Morris et al. (2006) pointed out that many habitats may take decades or even a century or more to develop the full compensatory values of lost vegetation systems. However, even defining or categorizing those values may be difficult.

In practice, habitat-based offsetting for individual insect species or populations tends to be viewed as a short-term operation, and so poses both ethical and practical problems, the balance of these varying between individual cases, and reflecting the ease of defining and providing sites and/or resources, the need for long-term commitment (countering the expectations of some developers viewing it as a 'quick fix' to expedite their development plans), and lack of knowledge of the species involved, particularly their ecology, population structure and landscape geometry needs. Attractions to developers can include (1) a costeffective means to comply with environmental and planning laws; (2) faster processing times for approval; (3) 
greater certainty over requirements than may be available from less formal appraisals; (4) opportunity to display/ demonstrate corporate social responsibility, and (5) through the use of credit schemes to pass obligations to third parties with capability to produce good conservation outcomes (BlakeDawson 2008). Semi-planned offset provisions, sometimes involving rehabilitation of sites, may make it easier for key sites for insects to be sacrificed on the purported basis that they are being replaced, but most commonly the outcomes are not known before development ensues. The golden sun-moth (Synemon plana, Castniidae) has been a focus of considerable discussion on habitat offset processes and practice in south eastern Australia. The moth is subject variously to protection under EPBC and the three local acts applying to New South Wales, Victoria and the Australian Capital Territory, and in all these areas, populations occur on patches of remnant native grassland. Many of these patches are small, and threatened by urban and industrial development, particularly around Canberra and to the north and west of Melbourne. The moth is difficult to survey properly (Gibson and New 2007) and many gaps in knowledge of its biology and population dynamics persist. Pressures for development of many of these sites, most of them on private land and not routinely managed for conservation (although supporting some of the largest sun-moth populations known: Gilmore et al. 2008), are likely to increase over the next few years. Translocations of the moth have not yet been trialed effectively, and are currently regarded as high risk, so that the preferred conservation option is generally to preserve sites rather than to pursue offset mitigation involving restoration of substitute sites, which are themselves sparse in the landscape.

The extent of 'recovery' on any site proposed for offset is also usually difficult to assess. A further dilemma is that techniques for restoration or to support offsets have not been defined specifically for most candidate species, and the critical resources needed as a basis for this have not been defined (Dennis et al. 2006). Offsets are thus generally framework habitats that can be based on only the most obvious resource needs of any particular threatened species. Many may have to be devised 'on the run' to meet needs of unexpected crises. In 2004, a colony of the threatened lycaenid Paralucia spinifera (Bathurst copper or purple copper) was discovered unexpectedly within the boundaries of an already proceeding road realignment project in the Central Highlands of New South Wales, with the original proposal likely to destroy up to $75 \%$ of the population. The discovery (in 2004) led to cessation of roadwork and preparation of a butterfly management plan through which more than a third of the area designated earlier for loss was retained. Additional measures included relocating as many caterpillars as possible into the retention area, replacing lost plants of the larval food Bursaria spinosa with a similar number of planted individuals, and general improvement to habitat quality-for example by weed removal. This mitigation could have been achieved only with cooperation between all parties involved (Mjadwesch and Nally 2008) and initial outcomes appear to have been successful, pending continued monitoring and evaluation. This outcome may be exceptional under these circumstances, and redesigning a project such as this at a late stage is costly; such needs are clearly best to be avoided by thorough assessment of risk to threatened species in early stages of planning a development proposal. Effective agency-developer liaison is indeed necessary, but it is important also to recognize that planning for any proposed offset may entail original research to clarify the real needs of the target species, and that the outcome is by no means assured. In Australia, most exercises of this nature are in their infancy, so that novel problems are likely to continue to arise.

Elsewhere in the world, a longer term mitigation programme, for a threatened riverine cerambycid beetle (Desmocerus californicus dimorphus, Valley elderberry longhorn beetle) has been in place in California for some 20 years to compensate for the loss of large numbers of foodplants (Sambucus mexicanus, blue elderberry and possibly other species of Sambucus, within which the larvae feed). It exemplifies other aspects of the process. The plant has been reduced considerably through agricultural and urban development, including pesticide use, linked to decline of the beetle through habitat loss and fragmentation. Mitigation has involved plantings of stems, with an initial ratio of 3.5:1 (compensation:impact), later increased substantially (Talley et al. 2006). Many plantings were not in riparian areas, thus not likely to provide prime habitat for the beetle, so that a prime conservation issue is placement of mitigation measures to assure or maximize effectiveness. Survival across sites is extremely variable, and lack of knowledge of the beetle's dispersal capability and population dynamics in relation to plantings also reduces reliability of the exercise. One recommendation from Talley et al. is to target sites adjacent to known beetle populations; another is to plant a mixture of seedling elderberries and older plants to provide variety, together with other plants found naturally in the areas. Sites of restored habitat are very small in relation to the areas lost. Despite strong positive intent, it seems that the tangible benefits of offset mitigation measures undertaken since the initial recovery plan for the beetle in 1984 have yet to be confirmed.

As a policy to increase conservation awareness habitat offsets may indeed have value (Morris et al. 2006), as long as the limitations of translating its immediate appeal into practice are acknowledged, and the difficult issues of 
effective compliance are met. The three species mentioned above illustrate a range of the contexts and problems that may arise for threatened insects in even relatively simple ecological situations, and that may not become apparent until after commitment is made. At this stage, plans for compensatory habitats for many insects can not be relied on as means to counter loss of high quality habitats already occupied by those species. Sacrifice of any such primary habitat to development thus remains a serious consideration, and a step to be avoided wherever possible.

Acknowledgments I thank Professors Roger Dennis and Michael Samways for perceptive comments on a draft of this note.

\section{References}

Australian Government (2007) Use of environmental offsets under the Environment Protection and Biodiversity Conservation Act 1999. Discussion Paper. Department of the Environment and Water Resources, Canberra

BlakeDawson (Nelson R, Day N, Jamieson R, Hill T) (2008) Environmental matters (national) (5/06/2008) Biodiversity: can you bank on it? (www.blakedawson.com/templates/publications/ x_article_content_page.aspx?id...). Accessed 21 October 2008

Dennis RLH, Shreeve TG, Van Dyke H (2006) Habitats and resources: the need for a resource-based definition to conserve butterflies. Biodiv Conserv 15:1943-1966

Gibbons P, Lindenmayer DB (2007) Offsets for land clearing: no net loss or the tail wagging the dog? Ecol Manag Restor 8:26-31

Gibson LA, New TR (2007) Problems in studying populations of the golden sun-moth, Synemon plana (Lepidoptera: Castniidae), in south-eastern Australia. J Insect Conserv 11:309-313

Gilmore D, Koehler S, O'Dwyer C, Moore W (2008) Golden sun moth Synemon plana (Lepidoptera: Castniidae): results of a broad survey of populations around Melbourne. Vic Nat 125:39-46

Mjadwesch R, Nally S (2008) Emergency relocation of a purple copper butterfly colony during roadworks: successes and lessons learned. Ecol Manag Restor 9:100-109

Morris RKA, Alonso I, Jefferson RG, Kirby KJ (2006) The creation of compensatory habitat-can it secure sustainable development? J Nat Conserv 14:106-116

Talley TS, Wright D, Holyoak M (2006) Assistance with the 5-year review of the Valley elderberry longhorn beetle (Desmocerus californicus dimorphus). US Fish and Wildlife Service, Sacramento 